system and the practices of establishing of such a system. The chapter starts by introducing transformation methods between, for example, different geodetic coordinate systems and different geodetic Cartesian coordinate systems. Attention focuses next on the geocentric coordinate system itself, and its many application. Some of these applications include construction layout, navigation, and space technology. The conventional terrestrial reference system (CTRS) and coordinate terrestrial reference frame (CTRF) are both explained in detail. This preliminary discussion paves the way for a comprehensive look at the different geodetic coordinate systems in use by China. The bulk of the attention is focused on the China Geodetic Coordinate System 2000.

An extensive bibliography of approximately 250 sources and an index concludes the book.

Like many fields, geodesy has witnessed important technological changes in recent decades. Geodesy: Introduction to Geodetic Datum and Geodetic Systems presents a comprehensive overview of the field that includes both classical approaches to geodetic measurement techniques and modern practices with satellite geodesy. There isn't anything shockingly new regarding the treatment of classical geodetic methods here-in fact, other texts provide a more comprehensive review of classical geodesy. However, that is not is not this book's strength, which lies in explaining the connection between classic and modern geodesy. This bridge is clearly present in the authors' Chapter
7 discussion of China's evolution of a geodetic coordinate system, which takes the reader through an interesting journey detailing decades of coordinate system development.

An allied strength of Geodesy comes in the considerable breadth of material presented. While some geodesy texts may delve into great detail on a selected number of topics, Geodesy discusses an extensive list of topics that widely samples from the field. While the discussions are at times thinly presented, the reader is introduced to many topics that might otherwise not be covered. Most topics are described in sections comprised of short paragraphs, making it easy for the reader to quickly grasp the material. Copious equations are found throughout the chapters, many of which include worked examples. To help elucidate the topics, the authors have provided many real-world examples. There are numerous illustrations includedmostly black and white line drawings- that help to illustrate specific concepts. A separate listing of the figures and equations would have made it easier for the reader to find a specific one, but this helpful addition is not included.

Overall, this is not a book for the faint of heart. It is packed full of dense information on a topic that is fundamentally complex. One should think of this book as more encyclopedic in its presentation instead of something that is to be read cover to cover-although certain readers will undoubtedly want to take that approach. If your work involves geodesy, or is tangentially related to the field, this book is an important reference.

\title{
THE FENCE AND THE BRIDGE: GEOPOLITICS AND IDENTITY ALONG THE CANADA-US BORDER
}

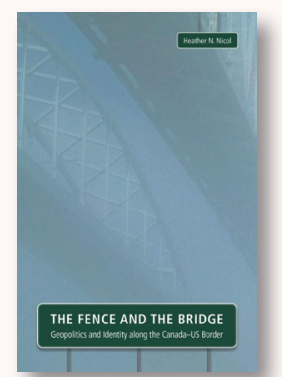

By Heather N. Nicol

Wilfrid Laurier University Press, 2015

296 pages, $\$ 34.39$ softcover, $\$ 39.58$ Kindle e-book.

ISBN: 978-1-55458-971-5

Review by: James C. Saku, Frostburg State University

Humans tend to claim ownership of specific territories, and boundary issues between individuals, groups, and countries are nothing new. They have been common both among nomadic groups and among those living more sedentary lives. It is unsurprising, then, that Canada and the United States have had a long history of border disputes arising from various economic and political issues.

The Fence and the Bridge: Geopolitics and Identity along the Canada-US Border is an engaging book that presents a very comprehensive analysis of the historical and contemporary issues that have shaped the border between these two nations. The first of its eight chapters examines the Canada-United States border relationship in the late eighteenth and early nineteenth centuries. At that time, the border between both countries was considered an unstable frontier that effectively drifted north and south. The author, Heather Nicol, notes that while Canadians portrayed 
the Canada-US border as a wall or fence protecting them from the United States, Americans perceived the border as merely a thin line between the two countries.

Chapter 2 analyzes the role of the Canada-US border within the context of national identity, citizenship, and controls on immigration in both countries. Nicol indicates that the emergence of naturalized geopolitics, which involved nation-building on both sides, created a distinct difference in the way the border was perceived by people on either side. Canadians strongly resisted the potential threat of annexation by the United States, by forming a confederation of British North American colonies and promoting a national, Canadian identity, one in which multiculturalism played a key role. From its earliest days to the present, Canadian society and politics have valued racial tolerance and multiculturalism. This formed a sharp contrast with the self-image of the United States, which viewed itself as a cultural melting pot. Similarly, the relationship between the Government of Canada and the First Nations is fundamentally different from that between the Government of the United States and Native Americans. While Canadians maintain a partnership relationship with their indigenous population, the US policy is one of custodianship.

The third chapter focuses on the role of the evolving economic relationship between the two countries, which played a role in defining and explaining their border. During the late nineteenth century, there was a tremendous flow of capital from the United States to Canada, and Canadians came to be dependent on US investment, particularly in regard to the exploitation of natural resources. This capital flow led to the establishment of American companies in Canada. During the same period, however, Canadians were involved in the exploitation of natural resources for the US market. This relationship was considered cordial and beneficial to both countries. However, as Nicol points out, cross-border trade of both industrial and agricultural goods was subject to taxation by both countries, a practice each saw as an integral part of a national trade strategy. To regulate duties on goods crossing the national boundary, a customs house was constructed in Saint-Jean-sur-Richelieu, Québec, on the old route between New York and Montréal.

The emergence of the more recent and harmonious border relationship that exists between Canada and the United States is examined in Chapter 4. While the boundary had been for the most part defined by an 1818 treaty, it was not completely surveyed until about 1874 . In 1908 , the two countries signed a treaty that established an International Boundary Commission (IBC). Made up of two commissioners, one from each country, the IBC was assigned the responsibility of remarking and refining the boundary between the two countries from the Atlantic to the Pacific coasts. In addition to the IBC, a joint commission was created to deal with disputes pertaining to the waterways used by both countries. Later, in the early twenty-first century, Canada and the US initiated a partnership on border issues that set common goals, procedures, and governing institutions, and led to the development of common policies on trade and defense.

Chapter 5 deals with issues on the emergence of new approaches to border management and security. According to Nicol, institutionalization of the border became the norm in the late twentieth century under the North American Free Trade Agreement, and involved the development and implementation of new technologies for monitoring the biometric data of persons crossing the international boundary. This was done not because the old ways of managing the border were ineffective, but because expensive new techniques like retina scans and voice detection were perceived as providing a more reliable means of risk management. One important repercussion of this institutionalized approach is that it normalized extraterritorial border management. For example, the US Transportation Security Administration (TSA), which collects information on domestic and international flights landing in the United States, now operates extraterritorially, requiring that information about passengers flying between Canadian airports also be handed over.

In the sixth chapter, Nicol examines the sudden changes that $9 / 11$ brought to the previously harmonious CanadaUS trans-border relationship. After 9/11, many in the United States saw the Canadian border as a security threat, largely due to what Nicol believes to have been a misrepresentation of Canada's immigration policies. She supports this position by identifying several historical situations when the border was similarly perceived, falsely, as dangerous. These included the period after the American Revolution, the War of 1812, the Indian Wars, the American Civil War, and the Cold War. More recently-both in December 1999 when Ahmed Ressam (the so-called "Millennium Bomber") was arrested attempting to enter the US, and three years later in December 2002, 
when false reports of Pakistani terrorists entering New York State through Canada gained wide circulationpublic anxiety among Americans brought largely imaginary concerns about border security to a high pitch.

Chapter 7: "Canada, the Border and American Hegemony: Cosmopolitanism? Or Not?” examines the Canada-US border in light of how the concept of cosmopolitanism is understood on either side of the line. In the United States, the concept is tied to global influence, leadership, and exceptionalism, while Canadians see it in a more European way, as existing within the context of globalization. Where the view of the border from Canada is of a change of jurisdiction, the view from the south is of a metaphorical or physical wall. This US policy of isolationism contrasts with its concurrent policies claiming world leadership. Certainly, US National Strategy Documents authored between 1998 and 2010 reflect an assumption of US world leadership in all matters, but attempts to impose "leadership" through recent military and political adventures in Afghanistan, Iraq, and Ukraine have not really worked out well.

Nicol wraps up her findings in Chapter 8. She notes that while tariffs tended to inhibit trade between the two nations well into the twentieth century, these restrictions were gradually relaxed, leading to more open and interconnected trans-border relations. She concludes that, by the end of the century, Canadians had a twofold perception of the border: as a wall defending them from Americans, and at the same time as a gateway opening upon a mutually beneficial trade relationship. After 9/11, however, the implementation of new security policies, many involving new technologies, led to aggressive US border management practices, including demands for information on people living outside the United States. These extraterritorial demands challenge the continued existence of open border policies.

The Fence and the Bridge provides an extraordinary wealth of information about the evolution of the Canada-US border, and it reflects the author's extensive research into a broad range of historical and contemporary source materials. Especially interesting is Nicol's use of cartoons and sarcastic depictions of events between Canada and the US to illustrate or support arguments about border issues between the two countries.

However, while the figures are an important part of the book, they are not always easy for the reader to grasp, and it is at times difficult to relate them to the issues discussed in the text. It is not helpful when illustrations are placed quite far from the text that refers to them. For example, Figure 1.10 is cited for the first time on page 33, but the figure itself is placed on page 51 .

This book can be very difficult to read and understand, due largely to the author's extensive use of specialized terminology and jargon. The text's difficulty will likely pose a challenge to most undergraduate students, but graduate students (at least of political geography) should be okayalthough I, too, will admit to having to re-read several chapters, myself.

Public opinion is conspicuously absent from the book's discussions. The author should, perhaps, have talked to politicians and citizens in both countries about their perceptions of the border. This would have been particularly illuminating to the analysis in Chapters 4 through 8, which expressly deals with contemporary border issues. The border between Canada and Alaska was not extensively covered, although there was some discussion of the wider polar regions.

The author is a political geographer, and writes for a parochial audience, but students of history, anthropology, culture, political science, and international studies will all find The Fence and the Bridge very useful, reasonably priced, and affordable. Those interested in border questions, generally, or in the Canada-US border in particular, will find this book a worthwhile acquisition. 